\title{
Cerebral infarction due to carotid occlusion and carbon monoxide exposure III. Influence of neck vein occlusion
}

\author{
RUDOLF LAAS, JÖRG IGLOFFSTEIN \\ From the Department of Neuropathology, Eppendorf Hospitals, University of Hamburg, Hamburg, \\ Federal Republic of Germany
}

SUMMARY Unilateral cerebral infarcts were produced in the rat by ligation of one common carotid artery and a subsequent exposure to carbon monoxide. In animals which had undergone an additional ligation of the external jugular veins leading to a moderate increase of the cephalic venous pressure the outcome of the procedure was ameliorated significantly. Venous pressure elevation was thought to reduce the venous vascular resistance effectively by preventing the leptomeningeal veins from collapsing. Collapse of the leptomeningeal veins probably occurred during the severe carbon monoxide-induced hypotension causing a steep increase of cerebral vascular resistance.

There is evidence that the threshold value of cerebral perfusion pressure below which cerebral infarcts occur is conspicuously clear-cut. ${ }^{12}$ We presume that this in part can be attributed to the collapse of leptomeningeal veins, which is known to increase flow resistance. Since a collapsed vessel can be distended by adding a flow resistance to its outlet we tested the hypothesis that the incidence of hypotension-induced brain lesions could be reduced by elevating the cephalic venous flow resistance. We used a modified Levine procedure which has been described in detail. ${ }^{3}$

\section{Material and methods}

The experiments were performed with unstarved male albino rats of the Chbb:THOM strain.

Series $I$

In 88 of 175 animals (body weight: $300-400 \mathrm{~g}$ ) both external jugular veins were ligated at the time of unilateral common carotid artery ligation. Twenty-four hours later the carbon monoxide exposure (3000 ppm in room air, 90 minutes duration) was performed.

Address for reprint requests: Rudolf Laas, MD, Department of Neuropathology, Eppendorf Hospitals, University of Hamburg, Martinistrasse 52, 2000 Hamburg 20, Fed Rep Germany.

Received 6 August 1982 and in revised form 18 January 1983 Accepted 4 March 1983

\section{Series II}

Pathophysiological investigations. Fifteen animals (body weight: $300-400 \mathrm{~g})$ were anaesthetised with ketamine (125 $\mathrm{mg} / \mathrm{kg}$ body weight). The arterial blood pressure was measured distally and proximally to the common carotid artery ligation via PVC-catheters. The cephalic venous pressure was measured by means of silastic catheters which were inserted into one of the greater branches of one external jugular vein. Thereafter, both external jugular veins were occluded for two minutes by means of gentle compression. This manoeuvre was repeated seven times with intervals of 4 minutes. In the individual animal the mean arterial and venous pressures were computed from about 50 values each for the occlusion and nonocclusion episodes. In nine of the animals seven additional episodes of bilateral venous occlusion were performed during an exposure to carbon monoxide. For technical reasons the carbon monoxide exposure was by an intraperitoneal injection of technical carbon monoxide per $100 \mathrm{~g}$ body weight according to Fodor et al. ${ }^{4}$ The carboxyhaemoglobin (CO$\mathrm{Hb}$ ) concentration was determined discontinuously (for details see ref 3 ). In order to achieve steady state conditions occlusion of the jugular veins was not started before 20 minutes after carbon monoxide injection. The exposure was terminated by removing the gas from the abdominal cavity through a small incision made into the abdomina wall.

\section{Results}

\section{Series I}

Lethality. Thirteen of 87 control animals and three of 88 experimental animals died within 48 hours 

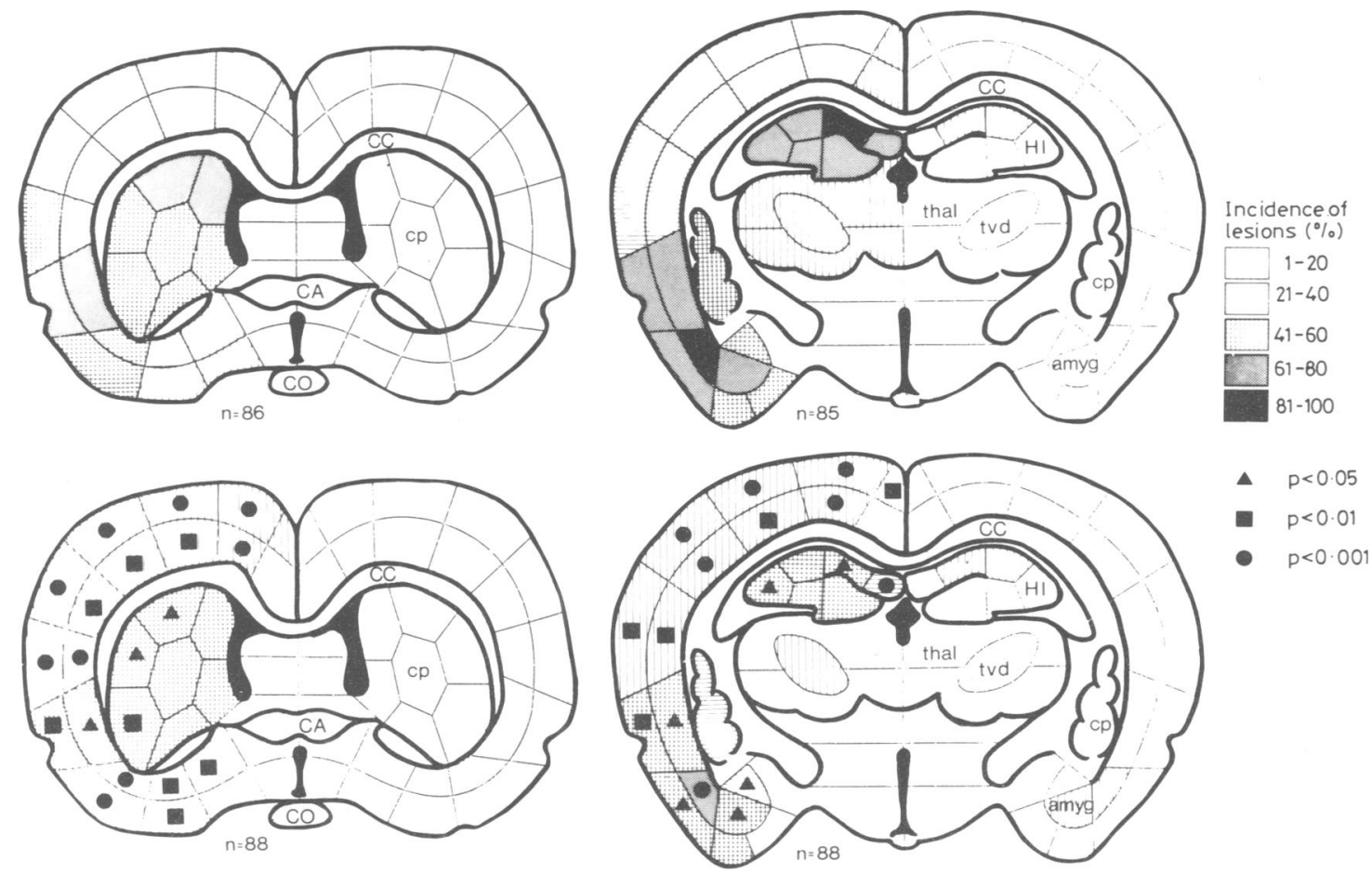

Fig 1 Pattern of infarct distribution in control rats (above) and in rats with bilateral ligation of the external jugular veins. For abbreviations see Ref 3, fig 4.

after the carbon monoxide exposure $(\mathrm{p}<0.001)$. The dead animals showed massive ipsilateral brain oedema.

Histological findings. As shown in fig 1 there was significantly less severe brain infarction in the experimental animals. There was no difference concerning the lesion pattern.

\section{Series II}

Pathophysiological findings. The venous pressure readings revealed fairly good interindividual consistency (fig 2). Bilateral occlusion of the external jugular veins raised the cephalic venous pressure from about 2 to about $12 \mathrm{~mm} \mathrm{Hg}$. The arterial blood pressure distal to the common carotid artery ligation was elevated by the venous occlusions nearly to the same extent as the cephalic venous pressure.

Before carbon monoxide injection the mean systemic arterial pressure fell by an average of $8 \mathrm{~mm}$ $\mathrm{Hg}$ after cephalic venous occlusion. As shown in fig 3 the intraperitoneal application of carbon monoxide induced circulatory changes quite similar to those recorded after inhalation of carbon monoxide. ${ }^{3}$ In contrast to the animals which inhaled carbon monoxide the heart rate rose again to $6 \mathrm{~Hz}$ at the end of the carbon monoxide exposure.

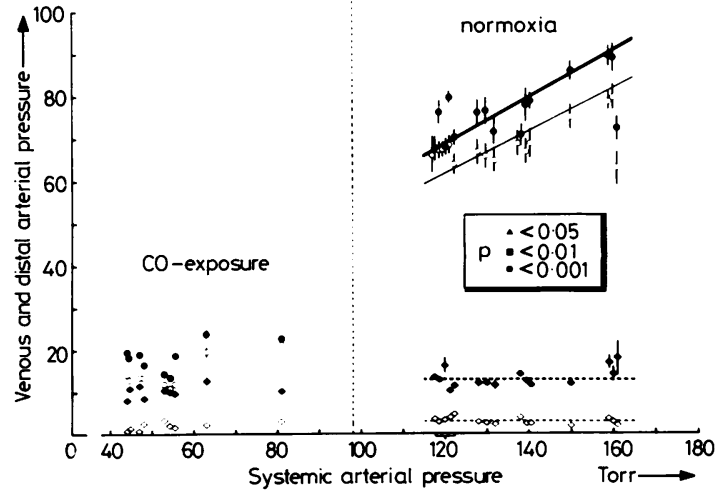

Fig 2 Cephalic venous pressure (rhombs), distal arterial pressure (circles) and systemic arterial pressure (abscissa) during normoxia (right side, 15 rats) and during carbon monoxide exposure (left side, 9 rats). Empty symbols: both jugular veins are open; filled symbols: both jugular veins are occluded. The values for the individual animals (mean, standard error of mean) are arranged in vertical rows. The lines represent computed regression lines. 


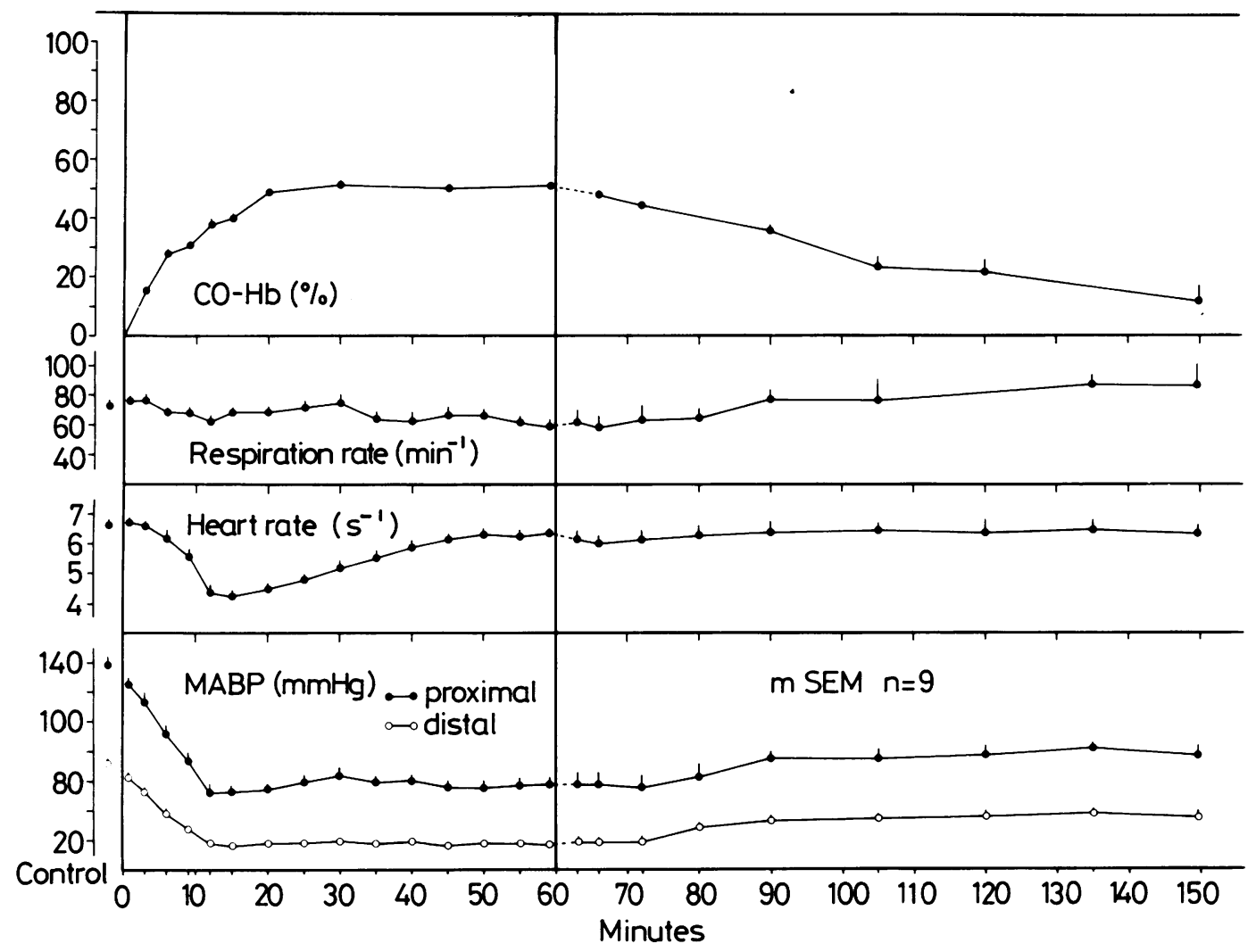

Fig 3 Changes in $\mathrm{CO}-\mathrm{Hb}$ concentration, mean arterial blood pressure (MABP), recorded proximally and distally to common carotid artery ligation, heart rate and respiratory rate during and following a carbon monoxide exposure being induced by intraperitoneal injection of $10 \mathrm{ml}$ of carbon monoxide per $100 \mathrm{~g}$ body weight.

Figure 2 demonstrates that the carbon monoxide exposure reduced the venous pressure response to occlusion of the neck veins to a smaller extent than the arterial one. Thus, the difference between the cephalic venous pressure and the distal arterial pressure fell from about $20 \mathrm{~mm} \mathrm{Hg}$ with the veins open to about $10 \mathrm{~mm} \mathrm{Hg}$ with the veins occluded.

\section{Discussion}

There is compelling evidence that a rise of cephalic venous pressure by $10 \mathrm{~mm} \mathrm{Hg}$, as achieved in our experiments, does not impair cerebral blood flow. In dogs, cerebral perfusion was not impeded even when the cephalic venous pressure was raised by 25 $\mathrm{mm} \mathrm{Hg}$ by constriction of the superior caval vein; rather there was a slight increase of cerebral blood flow (CBF) in most animals. ${ }^{5}$ Findings in healthy human test subjects, ${ }^{6}$ and in persons undergoing extracorporeal perfusion ${ }^{7}$ are in agreement with these data.
In contrast, in patients with widespread thrombotic occlusions of cerebral veins and sinuses a slight decrease of $\mathrm{CBF}$ has been measured. ${ }^{8}$ However, since all of these patients had suffered from severe neurological alterations (hemiplegia, focal seizures, longstanding drowsiness) 3 to 4 months before measurement of CBF, it is possible that the CBF depression was due to mechanisms other than venous obstruction.

Since the intraluminal pressure of the intracranial veins is linked to intracranial pressure over a wide pressure range, further evidence can be derived from the fact that CBF is not impeded until intracranial pressure is increased to $30-50 \mathrm{~mm} \mathrm{Hg} .^{9-12}$

The reduction of the cerebral perfusion pressure resulting from an increase of venous or intracranial pressure is likely to be compensated for by a proportionate dilatation of the cerebral vessels. This is thought to be mediated myogenically: ${ }^{13-15}$ the rigidity of the skull allows intracranial pressure increases to reduce the transmural pressure of the cerebral 
resistance vessels causing proportionate relaxation of the smooth muscle of the vessel wall. ${ }^{16}$ During the carbon monoxide-induced hypotension this compensatory mechanism cannot work within the hemisphere on the side of the common carotid artery ligation, since the distal arterial pressure is found to fall short of the lower threshold value of blood pressure autoregulation, being less than 50 to $60 \mathrm{~mm} \mathrm{Hg} .{ }^{13}{ }^{17}$ The capacity of the resistance vessels to dilate effectively is exhausted and their reactivity probably is further impeded by the functional anaemia and the slight acidosis. ${ }^{17}$

During carbon monoxide exposure venous ligation reduce the cerebral perfusion pressure by about $10 \mathrm{~mm} \mathrm{Hg}$, that is to about $50 \%$ of the pre-occlusion value (fig 2 ). The small increase of the distal arterial pressure which is found to occur when the veins are occluded during the carbon monoxide exposure (fig 2) probably reflected merely the consecutive increase of the overall cerebral vascular resistance. However, in spite of this considerable reduction of the cerebral perfusion pressure, the occlusion of the external jugular veins appeared to improve the perfusion rate of the ipsilateral hemisphere during the carbon monoxide-induced hypotension.

Within the physiological pressure range the leptomeningeal veins are prevented from collapsing by a valve-like mechanism which has been described as located at the entrance of the leptomeningeal veins into the dural sinuses. ${ }^{1819}$ The slit-like terminal segments of the leptomeningeal veins are more prone to compression than the circularly shaped leptomeningeal veins themselves. The flow resistance of these structures is thought to depend on the intracranial pressure providing the transmural pressure of the leptomeningeal veins to remain of positive value. ${ }^{91819}$ Collapse of the leptomeningeal veins may occur during severe global or regional hypotension, when intravascular pressure declines below that of the intracranial one. Although there are only scanty data available, collapse of the leptomeningeal veins probably takes place within the range of the blood pressure threshold value for infarct development which has been determined as about $25 \mathrm{~mm}$ $\mathrm{Hg} .{ }^{120} \mathrm{By}$ means of the cranial window technique the leptomeningeal veins have been observed to collapse at an arterial blood pressure just above $20 \mathrm{~mm}$ Hg. ${ }^{21}{ }^{22}$ The collapse was generalised. ${ }^{22}$ Our own preliminary observations through the thinned skull of rats seem to agree these findings but we wish to obtain additional data. In muscle venous collapse has been described when arterial pressure fell below $35 \mathrm{~mm} \mathrm{Hg}$. ${ }^{23}$

According to the physics of collapsible tubes, the collapse of the leptomeningeal veins causes a steep increase of the flow resistance. ${ }^{24} 25$ When collapse has occurred, elevation of the venous outflow resistance may distend the collapsed vessels and overall resistance may decrease sharply. Thus, in states of severe global or regional hypotension with the leptomeningeal veins being collapsed, elevation of the cephalic venous pressure may reduce flow resistance effectively. Flow may increase considerably although the overall perfusion pressure is lowered. Flow increase is not achieved by lowering the outlet pressure as observed in rigid tubes but paradoxically by raising it. ${ }^{24-26}$

In terms of our experiments it can be inferred that a cerebral perfusion pressure of about $10 \mathrm{~mm} \mathrm{Hg}$ with the veins being dilated provides a better tissue perfusion than does a cerebral perfusion pressure of $20 \mathrm{~mm} \mathrm{Hg}$ with the veins collapsed. On the other hand, this implies that the hypotensive threshold value for infarct development may at least in part be determined by the collapse of the leptomeningeal veins causing a steep decline or stop of cerebral blood flow. There is evidence that even small increases of CBF can ameliorate the outcome of cerebral ischaemia appreciably. ${ }^{27}$

It should be mentioned that Owens ${ }^{28} 29$ saw some-not significant-amelioration of the neurological outcome of unilateral brain infarcts produced in dogs by ligation of one medial cerebral artery, when an additional ligation of the superior caval vein was performed. The author attributed this effect to vasodilation due to hypercapnia and/or transient inversion of capillary flow. These tentative results may be readily explained by our findings. With normal oxyhaemoglobin levels the distal arterial blood pressure was elevated by occlusion of the neck veins to the same extent as the cephalic venous pressure (fig 2). Possibly, this indicates an additional increase of the precapillary vascular resistance which may be due to a so-called veno-vasomotor reflex. This is a myogenically mediated constriction of the resistance vessels which is thought to be due to a venous pressure elevation inducing a proportionate increase of the arteriolar transmural pressure..$^{30-32}$ This mechanism is known to exist within the vascular bed of the liver, the intestines, ${ }^{3031}$ and skeletal muscle. ${ }^{32}$ It seems justified therefore to assume that there is a veno-vasomotor reaction also within the extracranial vasculature of the cephalic muscles and glands. The veno-vasomotor reaction appears to represent a fundamental property of the vasculature. In favour of this assumption is the fact that within the intracranial vasculature an increase of the precapillary resistance can also be elicited by venous pressure elevation, when the intracranial compliance is increased by wide craniectomy, thus eliminating the above-mentioned compensatory mechanisms. ${ }^{14}$ 
Apparently, the veno-vasomotor reaction is not likely to elevate the cerebral perfusion rate when blood pressure autoregulation is preserved. Since myogenic vasomotor reactions are known to be abolished by hypoxia and acidosis, ${ }^{17}$ the amelioration of outcome in the rats which had undergone venous ligations can hardly be attributed to the veno-vasomotor reaction.

The slight decline of the systemic arterial pressure which was regularly measured after venous occlusions (affirming observations of others ${ }^{5}$ ) appears to be due to the dilatation of the cephalic capacitance vessels leading to a reduction of the circulating blood volume. ${ }^{33}$

In conclusion, our data suggest that in states of severe hypotension an increase of cephalic venous pressure improves cerebral perfusion by preventing the leptomeningeal veins from collapsing-in spite of reducing the cerebral perfusion pressure.

The authors are indebted to Mrs A Jakob for skilful technical assistance.

\section{References}

'Selkoe DJ, Myers RE. Neurologic and cardiovastular effects of hypotension on the monkey. Stroke 1979;10:147-57.

${ }^{2}$ Laas R, Arnold H. Brain infarction in the mongolian gerbil. Correlation between common carotid artery stump pressure, neurological symptoms and morphological findings. Acta Neurol Scand Suppl 72, 1979;60:340-1.

${ }^{3}$ Laas R, Igloffstein J, Meyerhoff S. Cerebral infarction due to carotid occlusion and carbon-monoxide exposure. I. Pathophysiological and neuropathological investigations. $J$ Neurol Neurosurg Psychiatry 1983;46:756-67.

${ }^{4}$ Fodor GG, Malorny G, Colmant HJ. Über die Beeinflussung des Elektroencephalogramms der Albinoratte nach einseitiger Carotisunterbindung und nachfolgender CO-Vergiftung. NaunynSchmiedebergs Arch Pharmakol 1964;249:215-24.

5 Jacobson I, Harper AM, McDowall DG. Relationship between venous pressure and cortical blood flow. Nature 1963;200:173-5.

${ }^{6}$ Moyer HJ, Miller SI, Snyder H. Effect of increased jugular pressure on cerebral hemodynamics. J Appl Physiol 1954;7:245-7.

${ }^{7}$ Juneja I, Flynn RE, Berger RL. The arterial, venous pressures and the electroencephalogram during open heart surgery. Acta Neurol Scand 1972;48:163-8.

${ }^{8}$ Shinohara Y, Takagi S, Kobatake K, Gotoh F. Influence of cerebral venous obstruction on cerebral circulation in humans. Arch Neurol 1982;39:479-81.

${ }^{9}$ Greenfield JC, Tindall GT. Effect of acute increase in intracranial pressure on blood flow in the internal carotid artery of man.J Clin Invest 1965;44:1343-51.
${ }^{10}$ Kety SS, Schmidt CF. The nitrous oxide method for the quantitative determination of cerebral blood flow in man. J Clin Invest 1948;27:476-83.

"Shulman K, Verdier GR. Cerebral vascular resistance changes in response to cerebrospinal fluid pressure. Am J Physiol 1967;213:1084-8.

${ }^{12}$ Häggendal E, Löfgren J, Nilsson NJ, Zwetnow NN. Effects of varied cerebrospinal fluid pressure on cerebral blood flow in dogs. Acta Physiol Scand 1970;79:262-71.

${ }^{13}$ Reivich M. Regulation of the cerebral circulation. Clin Neurosurg 1969;16:378-418.

${ }^{14}$ Ekström-Jodal B. Effect of increased venous pressure on cerebral blood flow in dogs. Acta Physiol Scand Suppl 1970;350:51-61.

${ }^{15}$ Kontos HA, Wei EP, Navari RM, Levasseur JE, Rosenblum WI, Patterson JL. Responses of cerebral arteries and arterioles in acute hypotension and hypertension. Am J Physiol 1978;234:H371-H383.

${ }^{16}$ Folkow B. Description of the Myogenic Hypothesis. Circ Res Suppl I, 1964;14, 15:I-279-I-285.

${ }^{17}$ Harper AM. General Physiology of Circulation. Int Anesthesiol Clin 1969;7:473-506.

${ }^{18}$ Nakagawa Y, Tsuru M, Yada K. Site and mechanism for compression of the venous system during experimental intracranial hypertension. $J$ Neurosurg 1974;41:427-34.

${ }^{19}$ Hacker H, Kühner G. Die Brückenvenen. Radiologe 1972;12:45-8.

${ }^{20}$ Graham DI, Fitch W, MacKenzie ET, Harper AM. Effects of hemorrhagic hypotension on the cerebral circulation. III. Neuropathology. Stroke 1979;10: 724-7.

${ }^{21}$ Brierley JB, Excell BJ. The effects of profound systemic hypotension upon the brain of $\mathbf{M}$. rhesus: Physiological and pathological observations. Brain 1966; 89:269-98.

${ }^{22}$ MacKenzie ET, Farrar JK, Fitch W, Graham DI, Gregory PC, Harper AM. Effects of hemorrhagic hypotension on the cerebral circulation. I. Cerebral blood flow and pial arteriolar caliber. Stroke 1979;10:711-8.

${ }^{23}$ Eriksson E, Lisander B. Low flow states in the microvessels of skeletal muscle in the cat. Acta Physiol Scand 1972;86:202-10.

${ }^{24}$ Brower RW, Noordergraaf A. Pressure-flow characteristic's of collapsible tubes: a reconciliation of seemingly contradictory results. Ann Biomed Eng 1973;1:33355.

${ }^{25}$ Rodbard S, Kuramoto $\mathrm{K}$. Transmural pressure and vascular resistance in soft-walled vessels. Am Heart J 1963;66:786-91.

${ }^{26}$ Rodbard S. Flow through collapsible tubes: augmented flow produced by resistance at the outlet. Circulation 1955;11:280-7.

${ }^{27}$ Steen PA, Michenfelder JD. Incomplete versus complete cerebral ischemia: improved outcome with a minimal blood flow. Ann Neurol 1979;6:389-98.

${ }^{28}$ Owens G. Evaluation of cerebral venous hypertension as therapy for cerebral infarction. Surg Forum 1960;10:764-7.

${ }^{29}$ Owens G. New concept in therapy of cerebral arterial insufficiency. NY St J Med 1964;64:1077-83. 
${ }^{30}$ Hanson KM, Johnson PC. Pressure-flow relationship in isolated dog colon. Am J Physiol 1967;212:574-8.

${ }^{31}$ Lutz J. Hämodynamische Eigenschaften und Gefäßreaktionen der intestinalen Strombahn. Arch Kreisl Forsch 1969;49:99-152.

${ }^{32}$ Nagle FJ, Scott JB, Swindall BT, Haddy FJ. Venous resistance in skeletal muscle and skin during local blood flow regulation. Am J Physiol 1968;214:88591.

${ }^{33}$ Kenner T. Über Kreislaufumstellungen nach Unterbindung großer Venenstämme bei der Ratte. Z Kreisl Forsch 1959b;48:1093-101. 